\title{
Editorial comment: the four principles and cultural specification
}

\author{
Teck-Chuan Voo
}

Received: 10 February 2009 / Accepted: 3 March 2009 /Published online: 19 March 2009

(C) Springer-Verlag 2009

\begin{abstract}
The four-principles approach of Beauchamp and Childress has had a huge influence in many areas of medicine, including Pediatrics. There is a risk that such universalist principles fail to take into account cultural differences. This is an important point but there is a need to see the more nuanced aspects of the approach.
\end{abstract}

Keywords Four-principles approach · Culture . Specification $\cdot$ Pediatrics

The four-principles approach (FPA) of Beauchamp and Childress has had a huge influence in many areas of medicine, including Pediatrics. However, as Westra et al. in this issue observe, there is a risk that such universalist principles fail to take into account cultural differences [3].

Westra et al. interpret the FPA as essentially a nonreligious ethics with commitments to "seemingly similar, but actually quite different principles" from a religiousbased ethics like Islamic morality. From this, they proposed an "alternative approach" that "pays genuine attention to different backgrounds." However, the application of the principles in context is something that Beauchamp and Childress (at least in later editions) do see as complex [1]. As they emphasize in the recent sixth edition of Principles of Biomedical Ethics, the principles are abstract starting points and need to be specified contextually for content in

T.-C. Voo $(\square)$

National University of Singapore,

Yong Loo Lin School of Medicine,

Centre for Biomedical Ethics,

Block MD11, \#02-04, Clinical Research Centre,

10 Medical Drive,

Singapore 117597, Singapore

e-mail: medvtc@nus.edu.sg order to serve as appropriate guides for ethical decisions, communication, and resolution. For the principles to be action-guiding in a particular culture and time, they need to be enriched by the established moral traditions of that culture and time.

As good "principalists", doctors must therefore be attentive towards the background of their patient and family in order to determine their professional obligations. So, if the parents of a dying child subscribe to particular Islamic beliefs about human freedom and choice, the principle of respect for autonomy could be specified as a norm not to seek explicit consent for withdrawal of treatment [2]. Furthermore, in line with the Islamic viewpoint that Westra et al. describe, the principle could also specify an obligation to disclose information that enables beneficent choices while helping to clear any doubts or address any concerns. If so, it is not unjustified paternalism for the healthcare team to stress to the parents the medically futile condition of their child and to clarify expressions such as "quality of life."

It is good that Westra et al. have raised these issues, as they are not well enough discussed at present. More cultural specifications of the principles, as the authors have done, would contribute well to the literature on the FPA.

\section{References}

1. Beauchamp TL, Childress JF (2009) Principles of biomedical ethics, 6th edn. Oxford University Press, New York

2. Beauchamp TL, Childress JF (2009) Respect for autonomy. In: Beauchamp TL, Childress JF (eds) Principles of biomedical ethics, 6th edn. Oxford University Press, New York, p 118

3. Westra AE, Willems DL, Smit BJ (2009) Communicating with Muslim parents: "the four principles" are not as culturally neutral as suggested. Eur J Pediatr. doi:10.1007/s00431-009-0970-8 